\title{
HSP90 inhibition blocks ERBB3 and RET phosphorylation in myxoid/round cell liposarcoma and causes massive cell death in vitro and in vivo
}

\author{
Setareh Safavi ${ }^{1}$, Sofia Järnum ${ }^{1}$, Christoffer Vannas ${ }^{1}$, Sameer Udhane ${ }^{1}$, Emma \\ Jonasson $^{1}$, Tajana Tesan Tomic ${ }^{1}$, Pernilla Grundevik ${ }^{1}$, Henrik Fagman ${ }^{1}$, Magnus \\ Hansson $^{1}$, Zeynep Kalender ${ }^{2}$, Alexandra Jauhiainen ${ }^{2}$, Soheila Dolatabadi ${ }^{1}$, Eva \\ Wessel Stratford ${ }^{3}$, Ola Myklebost ${ }^{3}$, Mikael Eriksson ${ }^{4}$, Göran Stenman ${ }^{1}$, Regine \\ Schneider Stock ${ }^{5}$, Anders Ståhlberg ${ }^{1}$, Pierre Åman ${ }^{1}$ \\ ${ }^{1}$ Sahlgrenska Cancer Center, Institute of Biomedicine, Department of Pathology, Sahlgrenska Academy, University of \\ Gothenburg, Gothenburg, Sweden \\ ${ }^{2}$ Mathematical Statistics, Mathematical Sciences, Chalmers University of Technology and the University of Gothenburg, \\ Göteborg, Sweden \\ ${ }^{3}$ Department of Tumour Biology, The Norwegian Radium Hospital, Oslo University Hospital, Nydalen, Oslo, Norway \\ ${ }^{4}$ Department of Oncology, Lund University Hospital, Lund, Sweden \\ ${ }^{5}$ Experimental Tumor Pathology, Institute of Pathology, University of Erlangen-Nürnberg, Ulmenweg Erlangen, Germany \\ Correspondence to: Pierre Åman, e-mail: pierre.aman@gu.se
}

Keywords: sarcoma, receptor tyrosine kinases, HSP9O inhibitors, xenografts

Received: April 27, 2015

Accepted: October 30, 2015

Published: November 16, 2015

\section{ABSTRACT}

Myxoid sarcoma (MLS) is one of the most common types of malignant soft tissue tumors. MLS is characterized by the FUS-DDIT3 or EWSR1-DDIT3 fusion oncogenes that encode abnormal transcription factors. The receptor tyrosine kinase (RTK) encoding RET was previously identified as a putative downstream target gene to FUS-DDIT3 and here we show that cultured MLS cells expressed phosphorylated RET together with its ligand Persephin. Treatment with RET specific kinase inhibitor Vandetanib failed to reduce RET phosphorylation and inhibit cell growth, suggesting that other RTKs may phosphorylate RET. A screening pointed out EGFR and ERBB3 as the strongest expressed phosphorylated RTKs in MLS cells. We show that ERBB3 formed nuclear and cytoplasmic complexes with RET and both RTKs were previously reported to form complexes with EGFR. The formation of RTK hetero complexes could explain the observed Vandetanib resistence in MLS. EGFR and ERBB3 are clients of HSP90 that help complex formation and RTK activation. Treatment of cultured MLS cells with HSP90 inhibitor 17-DMAG, caused loss of RET and ERBB3 phosphorylation and lead to rapid cell death. Treatment of MLS xenograft carrying Nude mice resulted in massive necrosis, rupture of capillaries and hemorrhages in tumor tissues. We conclude that complex formation between RET and other RTKs may cause RTK inhibitor resistance. HSP90 inhibitors can overcome this resistance and are thus promising drugs for treatment of MLS/RCLS. 


\section{INTRODUCTION}

Myxoid liposarcoma (MLS) accounts for more than a third of all liposarcoma cases [1]. This entity is characterized by $\mathrm{t}(12 ; 16)$ or more rarely $\mathrm{t}(12 ; 22)$ chromosome translocations that result in fusions of the transcription factor gene DDIT3 (also known as CHOP or GADD153) to FUS (also designated TLS) or to EWSR1 [2-4]. The chimerical FUS-DDIT3 and EWSR1-DDIT3 encoded proteins are believed to function as abnormal transcription factors and FUS-DDIT3 was reported to cause MLS like tumors in experimental mouse models $[3,5]$. Most MLS tumors carry normal and functional TP53 genes and are genetically stable $[6,7]$.

A subtraction screen for target genes downstream of FUS-DDIT3 identified the proto oncogene RET among genes that are expressed in FUS-DDIT3 carrying MLS, but not in normal adipose tissue or in benign lipoma [8]. RET encodes a receptor tyrosine kinase (RTK) [9-11] that may bind four alternative RET ligands. Ligand binding promotes RET complex formation, auto-phosphorylation [12] and activation of downstream signaling pathways [13-16]. RET can also form active heterodimers with the epithelial growth factor receptor (EGFR) [17] and recently the receptor tyrosine kinase MET was also reported to form heterodimers with RET in MLS tissues [18]. Such hetero-complex formation and activation of RET may operate in MLS cells as EGFR is strongly expressed in the tumor cells [19]. The observed co-expression of RET and EGFR in MLS prompted further investigation of RTKs as possible drug targets and their role in tumor development.

In the present study, we analyzed the expression of RET and its ligands in 8 MLS cases and 4 MLS derived cell lines and investigated its potential interaction with other RTK species. RTK inhibitors were tested for growth/ survival effects in MLS cell lines. The HSP90 chaperone proteins enlist RET and several other RTKs as client proteins [20, 21]. HSP90 inhibitors were thus tested for effects in MLS cell lines and in an MLS xenograft model.

\section{RESULTS}

\section{RET mRNA and protein is expressed in MLS cell lines and tumor tissues}

A meta-analysis of public expression array datasets from 434 human tumor samples, pointed out expression of RET as typically for MLS compared to other soft tissue tumors (Supplementary Data Table 1).

RT-PCR analysis with three primer pairs that amplified sequences encoding extracellular, transmembrane and tyrosine kinase encoding parts showed that full length RET transcripts were expressed in all MLS tumors investigated (Figure 1A). Western blot analysis of RET in protein extracts from three MLS cell lines showed reactive bands at $170 \mathrm{kDa}$, the reported size for the longest RET isoform (Figure 1B), and immunohistochemical (IHC) analysis of tumor tissues detected RET protein in both nuclei and cytoplasm of most tumor cells (Figure 1C).

\section{The RET protein is phosphorylated in MLS cells}

Ligands or activating mutations cause autophosphorylation of RET Y905 [22]. At least a fraction of the RET molecules reacted with a phospho-Y905 specific antibody in MLS (Figure 1B). Sequencing of four MLS cell lines showed that the Y905 phosphorylation was not caused by activating mutations in RET [6]. Other full exome sequencing efforts on large cohorts of MLS also report normal RET gene sequences [7].

\section{MLS tumors express the RET ligand Persephin but not co-receptors GFR $\alpha 1-4$}

Activation of RET could be caused by RET ligands in MLS. Our analysis of MLS cell lines showed that they contained mRNAs for glia derived neurotrophic factor (GDNF), neurturin (NRTN) and persephin (PSPN) but RNA extracted from tumor tissues contained only the $P S P N$ transcript (Figure 1A). Sequence analysis of $P S P N$ cDNA from MLS cell lines showed a normal $P S P N$ sequence (data not shown) and Western blot analysis of protein extracts from MLS cells showed two bands at the sizes reported for the unprocessed PSPN precursor $(17 \mathrm{kDa})$ and the mature PSPN (12 kDa) (Figure 1B). Both bands were detected with antibodies against $\mathrm{N}$-terminal and $\mathrm{C}$-terminal parts of PSPN. IHC analysis with PSPN specific antibodies in sections from eight MLS tumors showed a cytoplasmic staining of the tumor cells in all cases (Figure 1C). RT-PCR analysis of RET co-receptors GFR $\alpha 1-4$ in four MLS tumors and three MLS-cell lines detected no transcripts (data not shown).

\section{RET RTK inhibitor Vandetanib fails to block RET Y905 phosphorylation and cell growth/ survival of MLS derived cells lines}

The RTK inhibitor Vandetanib is reported to inhibit RET kinase activity with $50 \%$ inhibition at $100 \mathrm{nM}$ [23]. However, treatment of MLS cells with up to $2 \mu \mathrm{M}$ Vandetanib failed to reduce RET Y905 phosphorylation and cell proliferation/survival (Supplementary Figure 1A and 1B). The observed phosphorylation of RET Y905 may therefore depend on other, Vandetanib-resistant kinases.

\section{Phosphorylated EGFR and ERBB3 are expressed in MLS cells and tissues}

A dot blot screen for phosphorylated RTKs pointed out EGFR and ERBB3 as the most strongly expressed, 
phosphorylated RTKs in MLS cell lines (Figure 2A). Western blot analysis confirmed that EGFR (130 kDa) and ERBB3 (190 kDa) proteins were expressed in three MLS cell lines and that at least a fraction of these proteins were phosphorylated at their activation specific positions Y1068 and Y1289, respectively (Figure 2B). IHC studies of MLS tissues showed surface/cytoplasmic expression of EGFR whereas ERBB3 showed nuclear/cytoplasmic localization in MLS tissues and cell lines (Figure 2C).

\section{RET and ERBB3 proteins form complex in MLS cells}

RET and EGFR as well as EGFR and ERBB3 are known to form hetero-complexes [17, 24]. Our IHC observation that ERBB3 and RET partially co-localizes (Figures 1C and 2C), raised our suspicion that RET and ERBB3 also could form complexes. Proximity ligation assays
(PLA) showed that ERBB3 and RET localized close enough for PLA detection (Figure 2D), indicating that these molecules indeed form hetero-complex in MLS cells. The hetero-complex formation was confirmed by coimmunoprecipitation one word of RET with EGFP-antibodies in ERBB3-EGFP transfected MLS cells (Figure 2F).

Our IHC and PLA results showed a mixed cytoplasmic and nuclear expression of RET and ERBB3 (Figures 1C, 2C and Supplementary Film Clips).

\section{The EGFR tyrosine kinase inhibitor Gefitinib fails to inhibit cell growth/survival of MLS derived cells lines}

EGFR specific Gefitinib failed to inhibit cell growth and survival of MLS cell lines at concentrations with maintained RTK specificity [25] (Supplementary Figure 1C). Combinations of Gefitinib and Vandetanib also
A
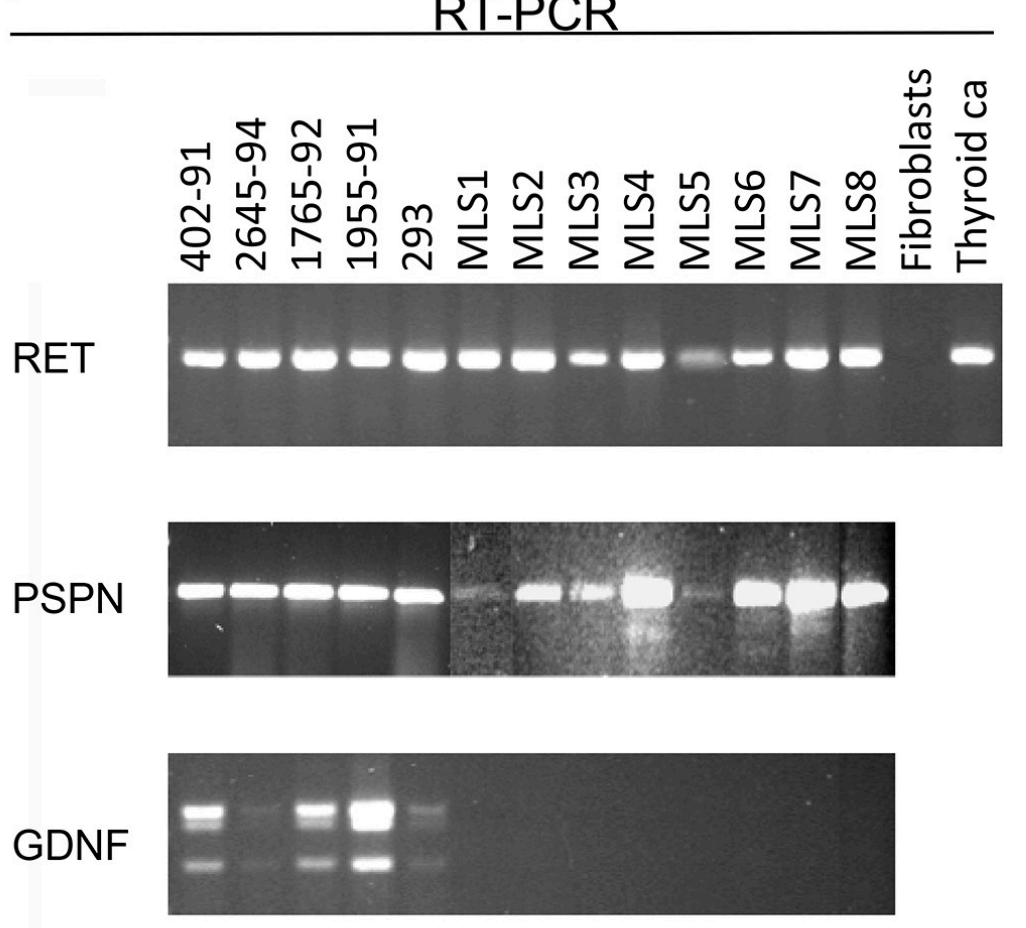

NRTN

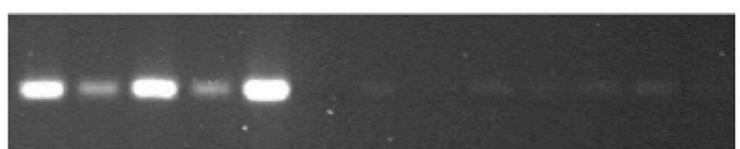

B
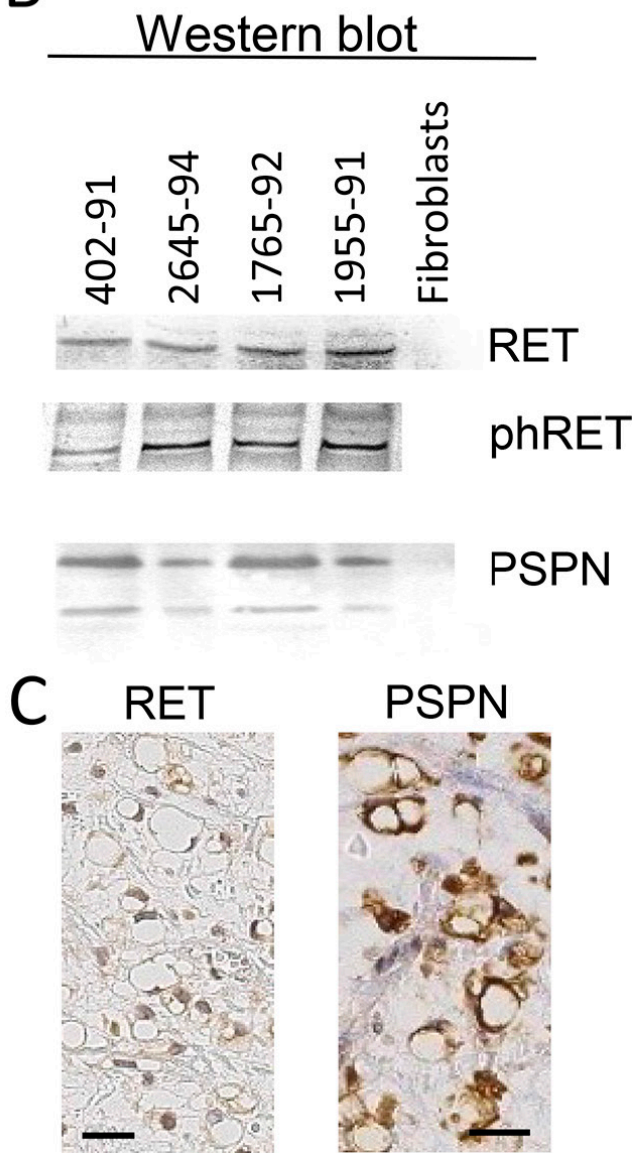

Figure 1: Expression of RET and ligands in MLS cell lines and tissues. (A) RT-PCR analysis of the tyrosine kinase encoding parts of the RET transcript and of ligands PSPN, GDNF and NRTN. Lanes 402-91, 2645-94, 1765-92 and 1955-91 are MLS derived cell lines, 293 is a short term cultured thyroid cancer, MLS 1-8 are material from MLS tumor tissues. Thyroid Ca is thyroid carcinoma tumor tissue sample used as positive control. Fibroblasts were used as negative control as they were previously found to be negative for RET expression [11]. (B) Western blot analysis of MLS cell lines 402-91, 2654-94, 1765-91 and 1955-91 and negative control fibroblasts. Antibodies against RET, RET phospho-Y905 and RET ligand PSPN C-terminal. (C) Immunohistochemistry of sections from one MLS case, representative of 8 tested. Sections stained with antibodies specific for the RET and PSPN proteins. Exclusion of the primary antibody abolished all staining of the sections. Size bars are $20 \mu \mathrm{m}$. 


\section{A}

Phospho-RTK array
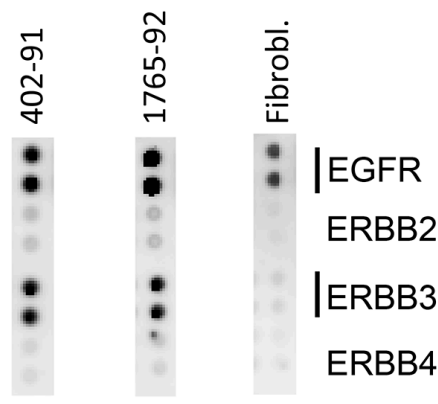

C

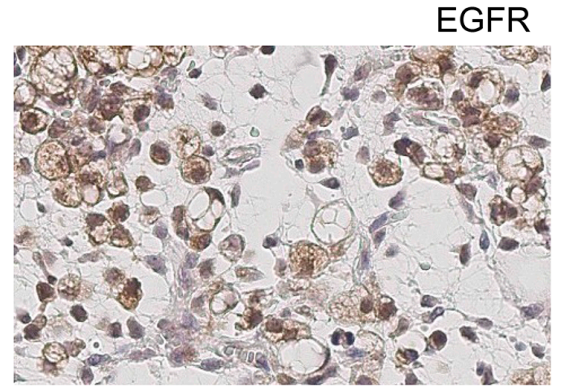

D

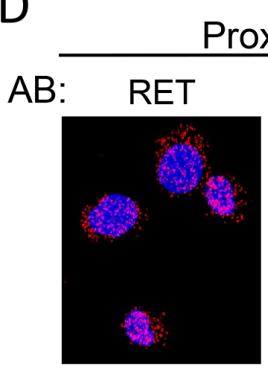

Proximity-ligation assay
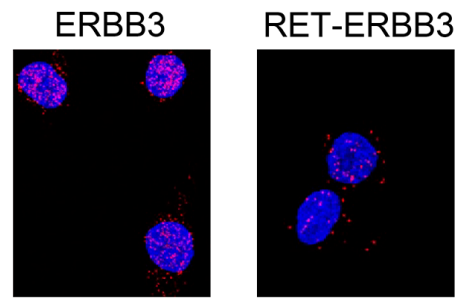

F

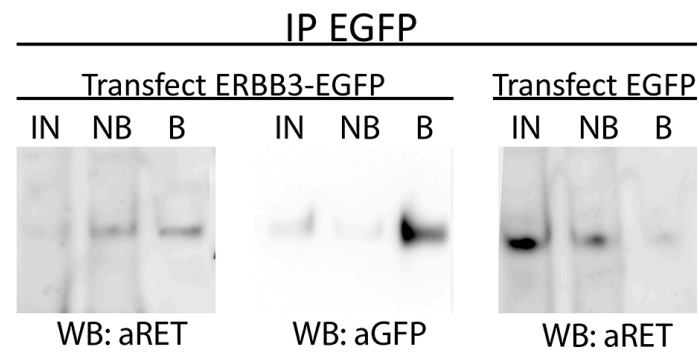

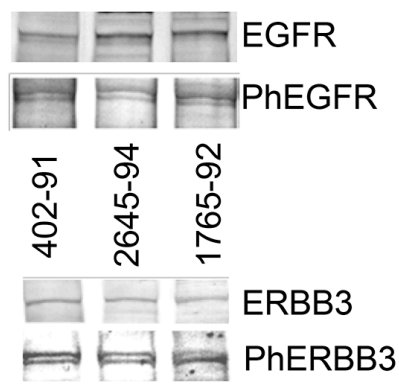

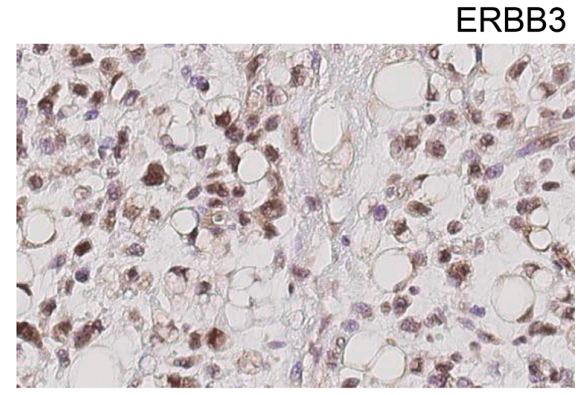

\section{E}

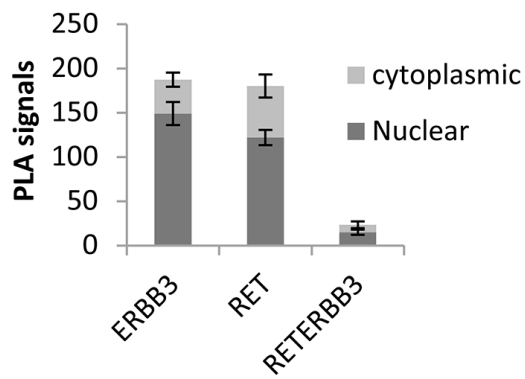

Figure 2: Expression of EGFR and ERBB3 in MLS cell lines and tissues. (A) RTK phospho-array analysis of MLS 402-91 and 1765-92 cell lines. Cultured normal fibroblasts as control sample. (B) Western blot analysis of EGFR, EGFR phospho-Y1068, ERBB3 and ERBB3 phospho-Y1289 in MLS cell lines 402-91, 2645-94, 1765-92. (C) Immunohistochemistry of sections from one MLS case representative of 8 . Sections stained with antibodies specific for the EGFR and ERBB3 proteins. Exclusion of the primary antibody abolished all staining of the sections. Size bars are $20 \mu \mathrm{m}$. (D) PLA analysis of RET-ERBB3 interaction. AB: indicates specificity of antibodies used. Red dots indicate signals from antibodies that are located close enough for the ligation assay to score. The RET and ERBB3 panels shows signals from antibodies targeting RET and ERBB3, respectively, and the RET-ERBB3 panel shows signals from interactions between one RET and one ERBB3 antibody as described in materials and methods. (E) Quantification of PLA signals from RET-RET, ERBB3-ERBB3 and RET-ERBB3 antibody combinations in cytoplasm and nuclei. Mean numbers of signals and standard error of means shown from five randomly selected cells of each experiment. (F) Co-immunoprecipitation of RET protein with EGFP antibodies in ERBB3EGFP and EGFP transfected MLS cell line 1765-92. Western blot detection of precipitated proteins is shown. IN: Input proteins for IP, NB: non-bound proteins, B: precipitated proteins. 
failed to block growth/survival at concentrations within their range of specificity (Supplementary Figure 1D).

\section{The HSP90 inhibitor 17-DMAG causes loss of phosphorylated RET, EGFR and ERBB3 proteins in MLS cell lines}

The failure to inhibit RET Y905 phosphorylation with specific tyrosine kinase inhibitors could possibly be explained by formation of multi-member protein complexes between RET, EGFR, ERBB3 and perhaps yet other tyrosine kinases. This hypothesis led us to investigate other means of modifying the activity of the RTKs. RET, EGFR and ERBB3 are listed among clients of HSP90 chaperone proteins [20, 21]. Cell proliferation and survival assays showed an LD50 between 10 and $30 \mathrm{nM}$ for the HSP90 inhibitor 17-DMAG in the tested MLS cell lines (Figure 3A). The RET Y905, and ERBB3 Y1289 phosphorylation levels were reduced 24 hours after addition of 17-DMAG while the total RET and ERBB3 protein levels were unaffected (Figure 3B).

\section{The HSP90 inhibitor 17-DMAG causes massive necrosis in xenografted MLS tumors}

An MLS tumor was serially transplanted in BALB/C NUDE mice and grew with the typical histological features of MLS (Figure 4A and Supplementary Figure 2A). Xenografts from two mice, each carrying two tumors, were treated for three days, one injection/ day with 17-DMAG. Three of four tumors showed hemorrhages with scattered extravasated erythrocytes and extensive coagulation type necrosis of tumor cells as well as of small vessels. The fourth and smallest tumor showed smaller affected areas and no hemorrhages. Four tumors analyzed after two weeks of treatment showed similar morphological changes. The extent of necrosis remained with a peripheral rim of viable tumor cells and without evidence of adipogenic maturation or stromal hyalinization (Figure 4B and Supplementary Figure 2B).

In a separate experiment, 4 animals, each carrying two tumors were given three injections of 17-DMAG with 48 hours intervals. This was repeated for two weeks with a 72 hours interval after the third injection. This treatment caused no dramatic changes in tumor size during, or immediately after the treatment period, but most tumors decreased slowly in size or halted their growth during an 83 day follow up period (Figure 4C).

\section{DISCUSSION}

Our previous search for possible downstream target genes of FUS-DDIT3 identified RET as a candidate [8] and meta-analysis of microarray data in this study confirmed expression of RET as a characteristic of MLS
(Supplementary Data Table 1). Expression of RET in MLS has independently been reported by others and higher expression level has been associated with poor survival $[18,26,27]$. Here, we show that PSPN, one GDNF-family member ligand of RET, is expressed in MLS and that the RET protein is phosphorylated at tyrosine 905 (Y905) as a sign of receptor activation [28-33]. PSPN binds to RET in complex with glycosyl-phosphatidylinositiol (GPI)anchored co-receptors GFRa 1-4 [13-15, 34, 35]. We did not detect any GFRa 1-4 transcripts in the tumors or cell lines. However, GFRa 1-4 independent ligand binding and RET signaling has been described [36], indicating a possible role for autocrine RET activation by PSPN in MLS. Expression of Artemin, another RET ligand and the RET coreceptor GFRa 3 has been reported in MLS by Negri et al. [18], but we have, for unknown reasons, not detected transcripts/proteins from these genes in our cohort of MLS. Taken together, the expression of RET in MLS and the reported function of RET in cell survival/growth mechanisms, suggests that this RTK may be important in MLS pathogenesis. These results also provided a rationale for trying to block RET Y905 phosphorylation with the RET specific TK inhibitor Vandetanib. This drug failed, however, to block RET Y905 phosphorylation or cell growth indicating that RET phosphorylation was maintained by a Vandetanib resistant kinase, possibly another RTK species that could form complex with RET.

Our screen for phosphorylated RTKs pointed out EGFR and ERBB3 as the most abundantly expressed in MLS. Using PLA and co-IP techniques, we showed, for the first time, that RET and ERBB3 form heterocomplexes. ERBB3 forms hetero-complexes with several other members of the EGFR RTK family but cannot form homodimers [24]. Adding to the complicated scenario of interacting RTKs, a previous report also suggest that RET may interact with and be phosphorylated by the MET RTK in MLS [18]. MLS cells thus contain at least four distinct RTK species (RET, EGFR, MET and ERBB3) that can form various complexes around RET. This could result in deregulated RTK activation and increased growth/survival of the tumor cells.

The finding that RET may form dimers with EGFR [17], provided a rationale for trying to block RET Y905 phosphorylation and growth/survival with the EGFR specific RTK inhibitor Gefitinib or combinations of Gefitinib and Vandetanib. No decrease in cell growth was observed at concentrations within the range of RTK specificity, indicating that the survival/growth supporting activity was maintained by a Gefitinib and Vandetanib resistant mechanism. The cytoplasmic tyrosine kinase SRC has been reported to phosphorylate RET at Y905 and promote RET protein activity [37]. This SRC activity could possibly explain the Vandetanib resistance of RET in MLS is compatible with the reported growth inhibiting and cytotoxic effects of a specific SRC inhibitor in MLS cells [38]. 
Our IHC analysis showed that RET and ERBB3 was expressed as cytoplasmic/nuclear proteins and this was confirmed by PLA analysis (Figure 2D, 2E and Supplementary Film Clips 1-3) and western blot analysis of cytoplasmic and nuclear cell fractions (Figure 3B) .
Nuclear, smaller variants of ERBB3 have been reported to bind the promoter and activate transcription of the cyclin D1 gene (CCND1) [39]. We could not detect shorter ERBB3 variants in MLS but found the full-length protein in nuclear MLS extracts (Figure 3A). A role for

\section{Effects of 17-DMAG treatment}

A



17-DMAG concentration (nM)

B

17-DMAG

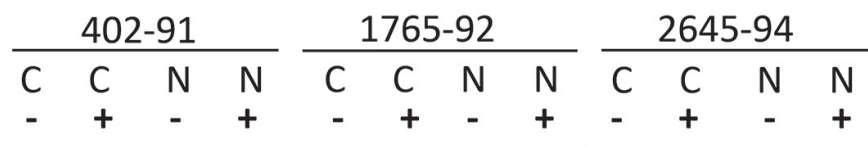

RET

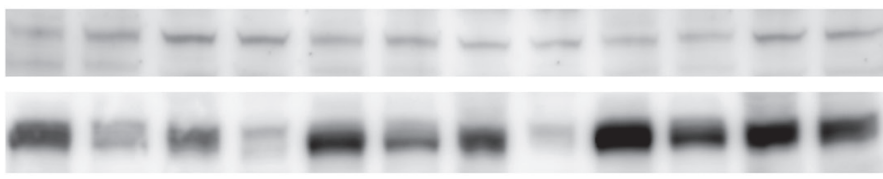

phRET

ERBB3

phERBB3

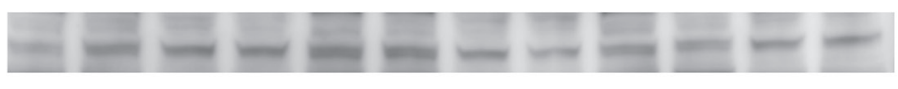

GAPDH

LAMIN
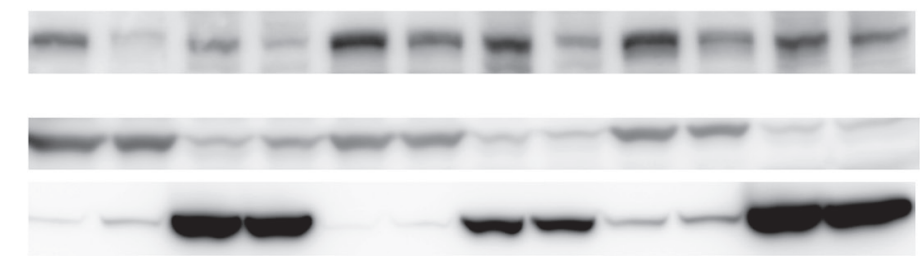

Figure 3: In vitro effects of 17-DMAG treatment. (A) Cell survival after 17-DMAG treatment. Cell density measured after 72 hours treatment of MLS cell lines (402-91, 1765-92 and 2645-94) and normal fibroblasts (F470) with various 17-DMAG concentrations. Values normalized against untreated control cells. Standard error of mean, indicated as error bars, was calculated from four replicates in different wells of the plate. (B) Western blot analysis of total and phosphorylated RTKs extracted from cytoplasmic and nuclear fractions of MLS cell lines after 24 hours of treatment with $30 \mathrm{nM}$ 17-DMAG as indicated. Nuclear and cytoplasmic fractions indicated by $\mathrm{N}$ and $\mathrm{C}$ respectively. Loading and fraction controls: GAPDH (cytoplasmic) and Lamin A (nuclear). 
nuclear ERBB3 in CCND1 regulation is compatible with the reported strong expression of CCND1 in MLS [19]. Nuclear expression and specific nuclear down-stream effects have been reported for many different RTK species including EGFR, ERBB3 and RET [40-43]. Nuclear RET expression was reported to cause phosphorylation of the apoptosis promoting transcription factor ATF4 and thus inhibit apoptosis and promote survival [43]. The nuclear expression of ERBB3 together with RET in MLS may thus be central for MLS pathogenesis.

We have previously reported a cytoplasmic/nuclear expression of the FLT1 receptor tyrosine kinase and its ligand PLGF in MLS [44]. Taken together, at least three RTK species (RET, ERBB3, FLT1)with two of their ligands (PSPN, PGF) show a nuclear localization in these cells. This unusual expression pattern stands out as
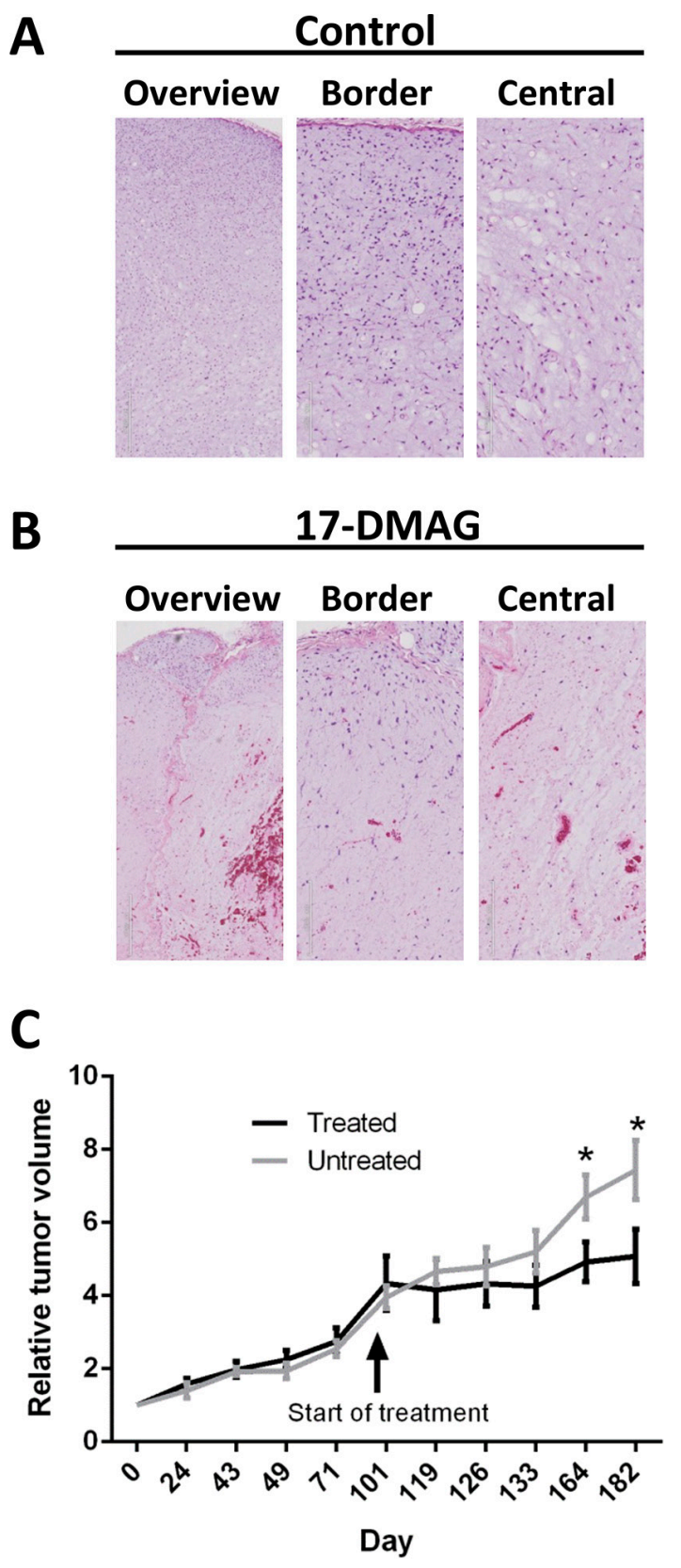

Figure 4: Histology of MLS xenografts from NUDE mice. (A) Control tissue showing typical MLS features with prominent myxoid matrix, lipoblasts and capillary vessels. Overview panel at 4 times, and close up border and central zone panels at 12 times magnification. (B) Tumor tissue one week after 3 days of 17-DMAG treatment, $25 \mathrm{mg} / \mathrm{Kg}$. Note extensive cell loss, rupture of capillary vessels and bleeding. See also microphotographs at higher resolution in Supplementary Figure 2. (C) Follow up on tumor volume in control and 17-DMAG treated animals. Time point for first injection at 100 days after first tumor measurement is indicated. Tumor growth was followed for 83 days after first injection. The mice were given three injections with 48 hours intervals, repeated for two weeks with a 72 hours break after injection 3. Data from 8 treated and 8 control tumors is shown as relative mean volumes using data from first measurements as base value. Standard error and significant differences according to $t$-test are shown as bars and stars. 
typical for MLS compared to normal mesenchymal cells. Cross activation between these and perhaps additional tyrosine kinases may thus be an essential function for selfsustaining growth and survival of MLS cells and could also cause the observed resistance to RTK inhibitors [45].

RTK activation and complex formation has been reported to depend on HSP90 activity $[45,46]$. Our data shows that inhibition of HSP90 functions lead to loss of RET and ERBB3 phosphorylation. It also caused growth cessation and death of MLS cells in vitro and extensive necrosis of xenografted MLS tumors. The cytostatic in vitro effects of HSP90 inhibition in MLS cell lines has recently been reported for an unrelated HSP90 inhibitor [47], confirming the MLS sensitivity to this class of drugs.

Several mechanisms for HSP90 inhibitor induced cell death have been described including inhibition/ degradation of RTKs [45, 46, 48-51]. HSP90 has a large number of client proteins and inhibition can be expected to affect many cellular functions leading to cell death. However, normal cells, including the human fibroblasts used as in vitro controls here, were highly resistant to HSP90 inhibitors. An outstanding difference between normal fibroblasts and MLS cells, is the co-expression and nuclear expression of RET and ERBB3. This difference may play an important role in the vulnerability of MLS cells exposed by HSP90 inhibition. The fact that 17-DMAG caused decreased ERBB3 and RET phosphorylation with maintained total levels of these proteins prior to cell death supports this conclusion.

Our in vitro results lead us to try HSP90 inhibitor treatment in an MLS xenograft model. This tumor has been serially transplanted from the patient and was not passaged in culture. It closely recapitulates the typical histology and slow growth pattern of MLS tumors. HSP90 inhibitor treatment caused massive cell death and bleeding/rupture of tumor capillaries. Macroscopically, the tumor tissues showed a slow decline or in some cases stable size. Histological examination revealed narrow marginal regions of surviving tumor cells several months after finished treatment. These surviving tumor cells may be senescent since MLS tumors contain major populations of resting and senescent cells [52]. Senescent cells are still capable of maintaining the extensive extracellular matrix [53], and could therefore prevent fast shrinkage of 17 DMAG treated tumor tissues. The small and slow size reduction of MLS tumors stands in contrast to the dramatic histological findings and has to be taken into consideration when clinical trials with MLS patients are to be evaluated.

We conclude that MLS cells express a mix of interacting RTKs and their ligands that could cross interact and cause their resistance to RTK inhibitors. Inhibition of HSP90 activity could overcome this resistance as shown by reduced RTK phosphorylation/proliferation and massive death of the tumor cells in vitro and in vivo. HSP90 inhibitors are therefore attractive drug candidates for treatment of MLS.

\section{MATERIALS AND METHODS}

\section{Tissue samples}

The tumor material is summarized in Table 1. Formaldehyde fixed tissues were embedded in paraffin and fresh tissues were frozen and stored at $-140^{\circ} \mathrm{C}$.

\section{Table 1: Cell lines and tissue samples}

\begin{tabular}{l}
\hline SAMPLE NUMBER \\
\begin{tabular}{|l|c|c|c|}
\hline $402-91$ & TUMOR TYPE & Cell line & FUS-DDIT3** \\
\hline $1955-91$ & MLS & Cell line & + \\
\hline $2645-94$ & MLS & Cell line & + \\
\hline $1765-92$ & MLS & Cell line & + \\
\hline Case1 & MLS & Tissue & + \\
\hline Case2 & MLS & Tissue & + \\
\hline Case3 & MLS & Tissue & + \\
\hline Case4 & MLS & Tissue & + \\
\hline Case5 & MLS & Tissue & + \\
\hline Case6 & MLS & Tissue & + \\
\hline Case7 & MLS & Tissue & + \\
\hline Case8 & MLS & Tissue & + \\
\hline Xenograft & MLS & Tissue & + \\
\hline
\end{tabular}
\end{tabular}

**Results from RT-PCR experiment 


\section{Cell culture and cell lines}

SV40 large T transformed myxoid liposarcoma cell lines 1955-91, 1765-92, 402-91 and 2645-94 [54-56], normal human fibroblasts F470, passages 4-8, MCF-7 (human breast cancer line), HT1080(human fibrosarcoma cell line [57]), were cultured in RPMI1640 with $8 \%$ fetal calf serum. All media and supplements were obtained from Life Technologies. Transfections were made with FUGENE 6 reagent (Promega) according to the manufacturers protocoll. ERBB3 cDNA clone (Addgene 23874) was inserted into a pEGFP-N1 vector (Clontech) and one control sequenced clone was used for transfection.

\section{Proliferation and cytotoxicity assay}

Cells were seeded to 96-well microtiter plates. Drugs were added after 24 hours at different concentrations. Each test was set up in three or more replicates. The medium was removed and plates were washed 72 hours after treatment and stored in $-80^{\circ} \mathrm{C}$ until analysis. The cells were lysed and DNA was stained using a Cell Proliferation Assay Kit (Molecular probes, C-7026) according to the manufacturers manual, and analyzed in a SpectraMaxGeminiXS (Göteborgs Termometerfabrik Gothenburg Sweden) or in a VICTOR ${ }^{3}$ multilabel plate reader (PerkinElmer).

\section{Nucleic acid extractions}

DNA was extracted from frozen tumor tissues as described [2]. RNA was extracted from tumor tissues using a Fastprep kit (Bio101) according to the manufacturer's recommendations. RNA was extracted from cultured cells as described [58].

\section{RT-PCR analysis}

RT-PCR analysis was performed with the following RET primers: RET225 5'-GGCTGCGTCTGCTGTGC TG and RET466 5'-AAGGTGAGGAGGCCGGTGTC, covering sequences encoding extracellular parts, RET 2185 5'-GCCCACAGCCACCCAT and RET 2469 5'-GGA GGCGTTCTCTTTCAGCATC, covering transmembrane encoding parts, RET2738 5'-TGGGCGACCTCATCTC ATTTG and RET3271 5'-AGGCCGTCGTCATAAATC AGGGAG, covering the tyrosine kinase encoding sequences of RET mRNA. For the analysis of ligand transcripts, the GDNF specific primers GDNFfwd 5'-ATGTCGTGGCTGTCTGCCTGG and GDNFrev 5'-CATCGCAAGAGCCGCTGCAG, the PSPN specific primers PSPN90fwd 5'-CGTGGCCGATGGAGAGTT CTC and PSPNrev 5'-AAGGCCACGTCGGTGTAGCG, the NRTN specific primers NTNfwd 5'-AGAGGGCC TGCTTCTCAGCC and NTNrev 5'-TAGCGGAACAGC ACCGTCTCG, and the ARTN specific primers
ARTNfwd 5'-TGCTGAGCAGCGTCGCAGAGG and ARTNrev 5'-AGGAGCCGCTGCAGAAGCGG, were used. To avoid amplification of contaminating genomic DNA, all primer pairs were designed to amplify cDNA fragments that spanned over one or several exon borders. Unigene representative sequences were used as template for primer design. PCR was run for 35 cycles using a GCRICH PCR system (Roche Diagnostics) and AmpliTaq GOLD Polymerase (Perkin-Elmer) according to the manufacturer's recommendations. PCR detection of FUSDDIT3 fusion transcripts was performed as previously described $[4,56]$.

\section{Mutation analysis}

Exons 10 and 11 of the RET gene were amplified from genomic tumor DNA by PCR using the following primers: CRT19S 5'-GCAGCATTGTTGGGGGACA (exon 10, forward), CRT2A 5'-GACAGCAGCACCGAGACGAT (exon 10, reverse), MENF 5'-CATGAGGCCGA GCATACTCAGCC (exon 11, forward), MENR 5'-CA GACAGCAGCGCCGAGACGATG (exon 11, reverse). Amplification was accomplished by 35 cycles using the following parameters: denaturation $94^{\circ} \mathrm{C}$ for 45 seconds, annealing $56^{\circ} \mathrm{C}$ for 90 seconds, extension $72^{\circ} \mathrm{C}$ for 90 seconds. PCR products were purified on Microspin S300 HR columns (Pharmacia Biotech, Uppsala, Sweden). An aliquot $(5-10 \mathrm{ml})$ of the purified PCR product served as template in a Big Dye Terminator Cycle Sequencing Ready Reaction procedure (PE-biosystems no 4303152) and the product was analyzed in an ABI PRISM 377 DNA sequencer (Perkin Elmer Biosystems, Foster City, CA). Forward primers were used for the sequencing procedure and each sample was analysed in at least three separate reactions. Sequences were analysed using the Sequence Navigator software.

\section{Immunohistochemistry (IHC)}

Sections were cut from blocks with formaldehyde fixed paraffin embedded tumor tissues, deparaffinized and stained with primary antibodies specific for RET and PSPN, (Santa Cruz Biotechnology, product numbers SC167 and SC-8684, respectively). The RET antibody was used at 1:100 dilutions whereas the PSPN antibody was applied at a 1:20 dilution. Exclusion or replacement of primary antibodies from the IHC protocol abolished all staining of the tissue sections.

\section{Proximity ligation assay}

The proximity ligation assays was performed with a DuoLink II kit(Olink Bioscience) according to the manufacturers protocols and as described [58]. DuoLink rabbit and goat specific probes were used in combination with ERBB3 specific rabbit antibody (G-4) (1:300) and 
RET specific goat antibody (C-19) (1:200), both from Santa Cruz Biotechnology. Assays with unmatched first antibodies and DuoLink probes and with single DuoLink probes were used as negative controls and gave no background signals.

Microphotographs were captured on a Zeiss LSM 700 confocal microscope and deconvolution, image analysis, quantification of PLA spots and animation clips were made with the Volocity soft-ware package, (PerkinElmer Inc). The deconvolution was performed using iterative restoration with a calculated point spread function.

\section{Western blots analysis}

Whole cell extracts were prepared as described [58] and separated on a 4-12\% SDS-PAGE gel (Life Technologies as previously described [59]. The proteins were blotted on Immobilon TM-P PVDF membranes (Millipore Corporation) or Invitrolon PVDF membranes (Life Technologies) and detected using the following antibodies: RET (C-19), goat polyclonal (Santa Cruz Biotechnology); phospho-RET Tyr-905, rabbit polyclonal (Cell Signaling Technology); Persephin (N18 and C17), goat antisera (Santa Cruz Biotechnology); EGFR (E30), mouse monoclonal (DAKO); phospho-EGFR Tyr-1068 (1H12), mouse monoclonal (Cell Signaling Technology); ERBB3 (G-4), mouse monoclonal (Santa Cruz Biotechnology); phospho-ERBB3 Tyr-1289 (21D3), rabbit monoclonal (Cell Signaling Technology); GFP (JL-8) mouse monoclonal (Clontech); GAPDH (mAbcam 9484), mouse monoclonal (Abcam); Lamin A (133A2), mouse monoclonal (Abcam). RP-conjugated secondary antibodies were used: Stabilized Goat Anti-Mouse IgG $(\mathrm{H}+\mathrm{L})$, Peroxidase Conjugated (Thermo Scientific Pierce); Stabilized Goat Anti-Rabbit $\operatorname{IgG}(\mathrm{H}+\mathrm{L})$, Peroxidase Conjugated (Thermo Scientific Pierce); bovine anti-goat IgG-HRP (Santa Cruz Biotechnology).

All antibodies were evaluated by tests on positive and negative control western blot samples and normal human tissue sections with published and established expression patterns of EGFR, ERBB3 and RET in specific cell types as described [19]. Extracts from human cultured fibroblasts were used as control for RET, Persephin and ERBB3 proteins. Breast cancer cell line MCF-7 was used as positive control of ERBB3.

Preparation of cytoplasmic and nuclear extracts was made from trypsin detached cell suspensions that were washed twice in PBS and suspended in $100 \mu \mathrm{l}$ of ice-cold lysis buffer containing $50 \mathrm{mM} \mathrm{NaCl}, 4 \mathrm{mM}$ $\mathrm{MgCl} 2,10 \mathrm{mM}$ TRIS PH 6. 8, 0, 5\% TritonX. The cells were disrupted by repeated pipetting for 5 minutes on ice. Nuclei were pelleted by centrifugation at $14000 \mathrm{rpm}$ for
15 minutes. Cytoplasmic (supernatant) and nuclear (pellet) fractions were collected and diluted 1: 4 with $4 \times$ NuPAGE LDS sample buffer (Life technologies) for Western blot analysis. Immunoprecipitation of GFP tagged ERBB3 was made 24 hours after transfection. Cells were harvested and suspended in lysis buffer (25 mM Tis $\mathrm{pH} 7.5,150 \mathrm{mM}$ $\mathrm{KCl}, 1,5 \mathrm{mM} \mathrm{MgCl}, 1 \mathrm{mM}$ DTT, and 0,5\% NP 40. After 30 minutes on ice followed by a 10 minutes centrifugation at $16000 \times \mathrm{G}$, the supernatant was diluted to $0,2 \%$ NP40. Immunoprecipitation was performed with GFP-TRAP beads (Chromotek) according to the manufacturers protocol.

\section{Animals and drug treatment}

Five to six weeks old BALB/C NUDE mice (Janvier Labs) were transplanted with approximately $2 \times 2 \mathrm{~mm}$ large tumor pieces. Mice with tumor sizes from $8 \times 8 \mathrm{~mm}$ were used for drug treatment tests. Tumor sizes were measured in $\mathrm{mm}$ with a caliper from 14 days after transplantation and volume calculated according to Feldman et al. [60]. 17-DMAG (Selleckchem) was dissolved in $150 \mathrm{mM} \mathrm{NaCl}$ to a final concentration of $1 \mathrm{mg} / \mathrm{ml}$ and stored frozen. The drug was administered by peritoneal injections ( $25 \mathrm{mg} / \mathrm{Kg}$ body weight). Drug treatment was started 114 days after transplantation with three injections at 48 hours intervals repeated for two weeks with a 72 hours break after injection 3. Tumor sizes were followed up for 83 days after first injection. The mice were sacrificed by cervical dislocation and tumors were immediately collected and transferred to ice-cold $4 \%$ formaldehyde in PBS.

\section{ACKNOWLEDGMENTS}

We thank the Centre for Cellular Imaging at the Sahlgrenska Academy, University of Gothenburg, for the use of imaging equipment and for the support from the staff.

This work was supported by grants from the Swedish Cancer Society, Assar Gabrielssons Research Foundation, Johan Jansson Foundation for Cancer Research, Socialstyrelsen, Swedish Society for Medical Research, Swedish Children's Cancer Society, BioCARE National Strategic Research Program at University of Gothenburg, Wilhelm and Martina Lundgren Foundation for Scientific Research, the Swedish Research Council and LUA-ALF grants of the Sahlgrenska Academy.

None of the authors report any potential conflicts of interest by publishing this report.

\section{CONFLICTS OF INTEREST}

The authors have no potential conflicts of interest. 


\section{REFERENCES}

1. Fletcher C, D, M, Unni K, K Mertens F. (2000). Tumors of soft tissue and bone. (Lyon: IARC Press).

2. Åman $\mathrm{P}$, Ron D, Mandahl N, Fioretos $\mathrm{T}$, Heim S, Arheden $\mathrm{K}$, Willen H, Rydholm A, Mitelman F. Rearrangement of the transcription factor gene CHOP in myxoid liposarcomas with $\mathrm{t}(12 ; 16)(\mathrm{q} 13 ; \mathrm{p} 11)$. Gene Chromos Canc. 1992; $5: 278-285$.

3. Crozat A, Åman P, Mandahl N, Ron D. Fusion of CHOP to a novel RNA-binding protein in human myxoid liposarcoma. Nature. 1993; 363:640-644.

4. Panagopoulos I, Hoglund M, Mertens F, Mandahl N, Mitelman F, Aman P. Fusion of the EWS and CHOP genes in myxoid liposarcoma. Oncogene. 1996; 12:489-494.

5. Rodriguez R, Tornin J, Suarez C, Astudillo A, Rubio R, Yauk C, Williams A, Rosu-Myles M, Funes JM, Boshoff C, Menendez P. Expression of FUS-CHOP Fusion Protein in Immortalized/Transformed Human Mesenchymal Stem Cells Drives Mixoid Liposarcoma Formation. Stem cells. 2013.

6. Stahlberg A, Kabjorn Gustafsson C, Engtrom K, Thomsen C, Dolatabadi S, Jonasson E, Li CY, Ruff D, Chen SM, Aman P. Normal and Functional TP53 in Genetically Stable Myxoid/Round Cell Liposarcoma. PloS one. 2014; 9:e113110.

7. Barretina J, Taylor BS, Banerji S, Ramos AH, LagosQuintana M, Decarolis PL, Shah K, Socci ND, Weir BA, Ho A, Chiang DY, Reva B, Mermel CH, et al. Subtypespecific genomic alterations define new targets for softtissue sarcoma therapy. Nature genetics. 2010; 42:715-721.

8. Thelin-Jarnum S, Lassen C, Panagopoulos I, Mandahl N, Åman P. Identification of genes differentially expressed in TLS-CHOP carrying myxoid liposarcomas. Int J Cancer. 1999; 83:30-33.

9. Mulligan LM, Kwok JB, Healey CS, Elsdon MJ, Eng C, Gardner E, Love DR, Mole SE, Moore JK, Papi L, et al. Germ-line mutations of the RET proto-oncogene in multiple endocrine neoplasia type 2A. Nature. 1993; 363:458-460.

10. Kalinin VN, Amosenko FA, Shabanov MA, Lubchenko LN, Hosch SB, Garkavtseva RF, Izbicki JR. Three novel mutations in the RET proto-oncogene. J Mol Med. 2001; 79:609-612.

11. Schuringa JJ, Wojtachnio K, Hagens W, Vellenga E, Buys CH, Hofstra R, Kruijer W. MEN2A-RET-induced cellular transformation by activation of STAT3. Oncogene. 2001; 20:5350-5358.

12. Taraviras S, Marcos-Gutierrez CV, Durbec P, Jani H, Grigoriou M, Sukumaran M, Wang LC, Hynes M, Raisman G, Pachnis V. Signalling by the RET receptor tyrosine kinase and its role in the development of the mammalian enteric nervous system. Development. 1999; 126:2785-2797.
13. Baloh RH, Tansey MG, Lampe PA, Fahrner TJ, Enomoto H, Simburger KS, Leitner ML, Araki T, Johnson EM, Jr. and Milbrandt J. Artemin, a novel member of the GDNF ligand family, supports peripheral and central neurons and signals through the GFRalpha3-RET receptor complex. Neuron. 1998; 21:1291-1302.

14. Fundin BT, Mikaels A, Westphal H, Ernfors P. A rapid and dynamic regulation of GDNF-family ligands and receptors correlate with the developmental dependency of cutaneous sensory innervation. Development. 1999; 126:2597-2610.

15. Creedon DJ, Tansey MG, Baloh RH, Osborne PA, Lampe PA, Fahrner TJ, Heuckeroth RO, Milbrandt J, Johnson EM, Jr. Neurturin shares receptors and signal transduction pathways with glial cell line-derived neurotrophic factor in sympathetic neurons. Proc Natl Acad Sci U S A. 1997; 94:7018-7023.

16. Milbrandt J, de Sauvage FJ, Fahrner TJ, Baloh RH, Leitner ML, Tansey MG, Lampe PA, Heuckeroth RO, Kotzbauer PT, Simburger KS, Golden JP, Davies JA, Vejsada R, et al. Persephin, a novel neurotrophic factor related to GDNF, neurturin. Neuron. 1998; 20:245-253.

17. Croyle M, Akeno N, Knauf JA, Fabbro D, Chen X, Baumgartner JE, Lane HA, Fagin JA. RET/PTC-induced cell growth is mediated in part by epidermal growth factor receptor (EGFR) activation: evidence for molecular and functional interactions between RET and EGFR. Cancer Res. 2008; 68:4183-4191.

18. Negri T, Virdis E, Brich S, Bozzi F, Tamborini E, Tarantino E, Jocolle G, Cassinelli G, Grosso F, Sanfilippo R, Casalini P, Greco A, Pierotti MA, Pilotti S. Functional mapping of receptor tyrosine kinases in myxoid liposarcoma. Clin Cancer Res 2010; 16:3581-3593.

19. Olofsson A, Willen H, Goransson M, Engstrom K, MeisKindblom JM, Stenman G, Kindblom LG, Aman P. Abnormal expression of cell cycle regulators in FUS-CHOP carrying liposarcomas. Int J Oncol. 2004; 25:1349-1355.

20. Alfano L, Guida T, Provitera L, Vecchio G, Billaud M, Santoro M, Carlomagno F. RET is a heat shock protein 90 (HSP90) client protein and is knocked down upon HSP90 pharmacological block. J Clin Enocrin Metab. 2010; 95:3552-3557.

21. Zuehlke A, Johnson JL. Hsp90 and co-chaperones twist the functions of diverse client proteins. Biopolymers. 2010; 93:211-217.

22. Takahashi M. The GDNF/RET signaling pathway and human diseases. Cytokine Growth Factor Rev. 2001; 12:361-373.

23. Carlomagno F, Vitagliano D, Guida T, Ciardiello F, Tortora G, Vecchio G, Ryan AJ, Fontanini G, Fusco A, Santoro M. ZD6474, an orally available inhibitor of KDR tyrosine kinase activity, efficiently blocks oncogenic RET kinases. Cancer Res. 2002; 62:7284-7290. 
24. Berger MB, Mendrola JM, Lemmon MA. ErbB3/HER3 does not homodimerize upon neuregulin binding at the cell surface. FEBS letters. 2004; 569:332-336.

25. Barker AJ, Gibson KH, Grundy W, Godfrey AA, Barlow JJ, Healy MP, Woodburn JR, Ashton SE, Curry BJ, Scarlett L, Henthorn L, Richards L. Studies leading to the identification of ZD1839 (IRESSA): an orally active, selective epidermal growth factor receptor tyrosine kinase inhibitor targeted to the treatment of cancer. Bioorg Med Chem Lett. 2001; 11:1911-1914.

26. Cheng H, Dodge J, Mehl E, Liu S, Poulin N, van de Rijn M, Nielsen TO. Validation of immature adipogenic status and identification of prognostic biomarkers in myxoid liposarcoma using tissue microarrays. Hum Pathol. 2009; 40:1244-1251.

27. Lanckohr C, Kasprzynski A, Klein-Hitpass L, Homann HH, Lehnhardt M, Muller O, Kuhnen C, Herter P. [Identification of genes over-expressed in myxoid/round cell liposarcoma. DNA microarray analysis and immunohistochemical correlation]. Der Pathologe. 2010; 31:60-66.

28. Alberti L, Borrello MG, Ghizzoni S, Torriti F, Rizzetti MG, Pierotti MA. Grb2 binding to the different isoforms of Ret tyrosine kinase. Oncogene. 1998; 17:1079-1087.

29. Arighi E, Alberti L, Torriti F, Ghizzoni S, Rizzetti MG, Pelicci G, Pasini B, Bongarzone I, Piutti C, Pierotti MA, Borrello MG. Identification of Shc docking site on Ret tyrosine kinase. Oncogene. 1997; 14:773-782.

30. Asai N, Murakami H, Iwashita T, Takahashi M. A mutation at tyrosine 1062 in MEN2A-Ret and MEN2B-Ret impairs their transforming activity and association with she adaptor proteins. J Biol Chem. 1996; 271:17644-17649.

31. Bongarzone I, Vigano E, Alberti L, Borrello MG, Pasini B, Greco A, Mondellini P, Smith DP, Ponder BA, Romeo G, Pierotti MA. Full activation of MEN2B mutant RET by an additional MEN2A mutation or by ligand GDNF stimulation. Oncogene. 1998; 16:2295-2301.

32. Liu X, Vega QC, Decker RA, Pandey A, Worby CA, Dixon JE. Oncogenic RET receptors display different autophosphorylation sites and substrate binding specificities. J Biol Chem. 1996; 271:5309-5312.

33. Xing S, Furminger TL, Tong Q, Jhiang SM. Signal transduction pathways activated by RET oncoproteins in PC12 pheochromocytoma cells. J Biol Chem. 1998; 273:4909-4914.

34. Golden JP, DeMaro JA, Osborne PA, Milbrandt J, Johnson EM, Jr. Expression of neurturin, GDNF, and GDNF family-receptor mRNA in the developing and mature mouse. Exp Neurol. 1999; 158:504-528.

35. Lindahl M, Poteryaev D, Yu L, Arumae U, Timmusk T, Bongarzone I, Aiello A, Pierotti MA, Airaksinen MS, Saarma M. Human glial cell line-derived neurotrophic factor receptor alpha 4 is the receptor for persephin and is predominantly expressed in normal and malignant thyroid medullary cells. J Biol Chem. 2001; 276:9344-9351.
36. Tsui-Pierchala BA, Milbrandt J, Johnson EM, Jr. NGF utilizes c-Ret via a novel GFL-independent, inter-RTK signaling mechanism to maintain the trophic status of mature sympathetic neurons. Neuron. 2002; 33:261-273.

37. Kato M, Takeda K, Kawamoto Y, Iwashita T, Akhand AA, Senga T, Yamamoto M, Sobue G, Hamaguchi M, Takahashi M, Nakashima I. Repair by Src kinase of function-impaired RET with multiple endocrine neoplasia type $2 \mathrm{~A}$ mutation with substitutions of tyrosines in the $\mathrm{COOH}$-terminal kinase domain for phenylalanine. Cancer research. 2002; 62:2414-2422.

38. Sievers E, Trautmann M, Kindler D, Huss S, Gruenewald I, Dirksen U, Renner M, Mechtersheimer G, Pedeutour F, Aman P, Nishio J, Schildhaus HU, Kirfel J, et al. SRC inhibition represents a potential therapeutic strategy in liposarcoma. Int J Cancer. 2015; 137:2578-2588.

39. Andrique L, Fauvin D, El Maassarani M, Colasson H, Vannier B, Seite P. ErbB3 (80 kDa), a nuclear variant of the ErbB3 receptor, binds to the Cyclin D1 promoter to activate cell proliferation but is negatively controlled by p14ARF. Cell Signal. 2012; 24:1074-1085.

40. Hsu SC, Hung MC. Characterization of a novel tripartite nuclear localization sequence in the EGFR family. J Biol Chem. 2007; 282:10432-10440.

41. Lemmon MA, Schlessinger J. Cell signaling by receptor tyrosine kinases. Cell. 2010; 141:1117-1134.

42. Adilakshmi T, Ness-Myers J, Madrid-Aliste C, Fiser A, Tapinos N. A nuclear variant of ErbB3 receptor tyrosine kinase regulates ezrin distribution and Schwann cell myelination. J Neurosci. 2011; 31:5106-5119.

43. Bagheri-Yarmand R, Sinha KM, Gururaj AE, Ahmed Z, Rizvi YQ, Huang SC, Ladbury JE, Bogler O, Williams MD, Cote GJ, Gagel RF. A novel dual kinase function of the RET proto-oncogene negatively regulates activating transcription factor 4-mediated apoptosis. J Biol Chem. 2015; 290:11749-11761.

44. Andersson MK, Goransson M, Olofsson A, Andersson C, Aman P. Nuclear expression of FLT1 and its ligand PGF in FUS-DDIT3 carrying myxoid liposarcomas suggests the existence of an intracrine signaling loop. BMC cancer. 2010; 10:249.

45. Ou WB, Hubert C, Corson JM, Bueno R, Flynn DL, Sugarbaker DJ, Fletcher JA. Targeted inhibition of multiple receptor tyrosine kinases in mesothelioma. Neoplasia. 2011; 13:12-22.

46. Lang SA, Klein D, Moser C, Gaumann A, Glockzin G, Dahlke MH, Dietmaier W, Bolder U, Schlitt HJ, Geissler EK, Stoeltzing O. Inhibition of heat shock protein 90 impairs epidermal growth factor-mediated signaling in gastric cancer cells and reduces tumor growth and vascularization in vivo. Mol Cancer Ther. 2007; 6: 1123-1132.

47. Steinmann S, Gali-Muhtasib H, Huebner K, Al-Halabi R, Abou Merhi R, Aman P, Agaimy A, Haller F, Schneider- 
Stock R. Hsp90 inhibition by AUY922 as an effective treatment strategy against myxoid liposarcoma. Cancer Lett. $2015 ; 367: 147-156$.

48. Andersson J, Rosestedt M, Asplund V, Yavari N, Orlova A. In vitro modeling of HER2-targeting therapy in disseminated prostate cancer. Int J Oncol. 2014; 45: 2153-2158.

49. Rice JW, Veal JM, Barabasz A, Foley B, Fadden P, Scott A, Huang K, Steed P, Hall S. Targeting of multiple signaling pathways by the Hsp90 inhibitor SNX-2112 in EGFR resistance models as a single agent or in combination with erlotinib. Oncol Res. 2009; 18:229-242.

50. Sawai A, Chandarlapaty S, Greulich H, Gonen M, Ye Q, Arteaga CL, Sellers W, Rosen N, Solit DB. Inhibition of Hsp90 down-regulates mutant epidermal growth factor receptor (EGFR) expression and sensitizes EGFR mutant tumors to paclitaxel. Cancer Res. 2008; 68:589-596.

51. Shimamura T, Lowell AM, Engelman JA, Shapiro GI. Epidermal growth factor receptors harboring kinase domain mutations associate with the heat shock protein 90 chaperone and are destabilized following exposure to geldanamycins. Cancer Res. 2005; 65:6401-6408.

52. Kåbjörn Gustafsson C, Ståhlberg A, Engström K, Danielsson A, Turesson I, Åman P. Cell senescence in myxoid/round cell liposarcoma. Sarcoma. 2014.

53. Choi AM, Olsen DR, Cook KG, Deamond SF, Uitto J, Bruce SA. Differential extracellular matrix gene expression by fibroblasts during their proliferative life span in vitro and at senescence. J Cell Physiol. 1992; 151:147-155.

54. Aman P. Fusion genes in solid tumors. Semin Cancer Biol. 1999; 9:303-318.

55. Goransson M, Elias E, Stahlberg A, Olofsson A, Andersson C, Aman P. Myxoid liposarcoma FUS-DDIT3 fusion oncogene induces $\mathrm{C} / \mathrm{EBP}$ beta-mediated interleukin 6 expression. Int J Cancer. 2005; 115:556-560.

56. Panagopoulos I, Mandahl N, Mitelman F, Aman P. Two distinct FUS breakpoint clusters in myxoid liposarcoma and acute myeloid leukemia with the translocations $t(12 ; 16)$ and $t$ (16;21). Oncogene. 1995; 11:1133-1137.

57. Rasheed S, Nelson-Rees WA, Toth EM, Arnstein P, Gardner MB. Characterization of a newly derived human sarcoma cell line (HT-1080). Cancer. 1974; 33:1027-1033.

58. Thomsen C, Udhane S, Runnberg R, Wiche G, Stahlberg A, Aman P. Fused in sarcoma (FUS) interacts with the cytolinker protein plectin: implications for FUS subcellular localization and function. Exp Cell Res. 2012; 318:653-661.

59. Goransson M, Andersson MK, Forni C, Stahlberg A, Andersson C, Olofsson A, Mantovani R, Aman P. The myxoid liposarcoma FUS-DDIT3 fusion oncoprotein deregulates NF-kappaB target genes by interaction with NFKBIZ. Oncogene. 2009; 28:270-278.

60. Feldman JP. A mathematical model for tumor volume evaluation using two-dimensions. J Appl Quant Meth. 2009; $4: 455-462$. 